\title{
A lifestyle intervention or metformin prevented or delayed the onset of type 2 diabetes in people at risk
}

\author{
Diabetes Prevention Program Research Group. Reduction in the incidence of type 2 diabetes with lifestyle intervention or \\ metformin. N Engl J Med $2002 \mathrm{Feb}$ 7;346:393-403.
}

\section{QUESTION: In overweight people with elevated fasting and postload plasma glucose concentrations, does a lifestyle intervention or treatment with metformin prevent or delay the onset of type 2 diabetes mellitus?}

\section{Design}

Randomised (allocation concealed), blinded (clinicians and participants for metformin and placebo), placebo controlled trial with a mean follow up of 2.8 years (range $1.8-4.6 \mathrm{y})$.

\section{Setting}

27 centres in the US.

\section{Participants}

3234 participants $\geq 25$ years of age (mean age 51 y, $68 \%$ women) without diabetes who had a body mass index $\geq 24 \mathrm{~kg} / \mathrm{m}^{2}$ ( $\geq 22 \mathrm{~kg} / \mathrm{m}^{2}$ for Asians), plasma glucose concentration of $5.3-6.9 \mathrm{mmol} / \mathrm{l}$ in the fasting state and $7.8-11.0 \mathrm{mmol} / 12$ hours after a $75 \mathrm{~g}$ oral glucose load. Exclusion criteria included taking medicines known to alter glucose tolerance and illnesses that could seriously reduce life expectancy or ability to participate in the trial. Follow up was $93 \%$.

\section{Intervention}

Participants were allocated to an intensive programme of lifestyle modification $(\mathrm{n}=1079)$ or standard lifestyle recommendations and glucose control with metformin, $850 \mathrm{mg}$ twice daily $(\mathrm{n}=1073)$, or placebo $(\mathrm{n}=1082)$. The intensive lifestyle intervention consisted of a 16 lesson, goal focused curriculum taught in flexible individualised one-on-one sessions supported by ongoing (approximately monthly) one-on-one and group sessions. The goals were to achieve and maintain a weight reduction of $\geq 7 \%$ of initial body weight through a low calorie, low fat diet and physical activity of moderate intensity for $>150 \mathrm{~min} /$ week. Standard lifestyle recommendations were given in writing and at annual one-on-one sessions of 20-30 minutes. Recommendations emphasised the importance of a healthy lifestyle aimed at reducing weight and increasing physical activity.

\section{Main outcome measures}

The main outcome was incidence of type 2 diabetes mellitus with a secondary focus on lifestyle changes.

\section{Main results}

Analysis was by intention to treat. At 3 years, the cumulative incidence of diabetes was lower in each of the lifestyle intervention and metformin groups than in the placebo group (table). The incidence rates of diabetes were $4.8,7.8$, and 11.0 patients per 100 person years for the lifestyle intervention, metformin, and placebo groups, respectively.

Mean weight loss was greater in each of the lifestyle intervention $(5.6 \mathrm{~kg})$ and metformin $(2.1 \mathrm{~kg})$ groups than in the placebo group $(0.1 \mathrm{~kg})(\mathrm{p}$ values $<0.001)$. Increase in leisure physical activity was greater in the lifestyle intervention group than in the combined metformin and placebo group $(\mathrm{p}<0.001)$.

\section{Conclusion}

In overweight people with elevated fasting and postload plasma glucose concentrations, a lifestyle intervention or treatment with metformin prevented or delayed the onset of type 2 diabetes mellitus.

Lifestyle intervention (LI) or metformin plus standard lifestyle v placebo plus standard lifestyle for prevention of type 2 diabetes at 3 years*

\begin{tabular}{lllll} 
Outcome & Comparisons & Event rates & RRR (95\% CI) & NNT (CI) \\
\multirow{2}{*}{ Incidence of diabetes } & LI $v$ placebo & $14 \% v 29 \%$ & $50 \%(41$ to 58$)$ & 7 (6 to 10) \\
\cline { 2 - 5 } & $\begin{array}{l}\text { Metformin } v \\
\text { placebo }\end{array}$ & $22 \% v 29 \%$ & $25 \%(13$ to 35$)$ & 14 (9 to 34$)$ \\
\hline
\end{tabular}

*Abbreviations defined in glossary; RRR, NNT, and $\mathrm{Cl}$ calculated from data in article.

\section{COMMENTARY}

Nurses in most specialties will encounter the challenge of providing good health care for the increasing numbers of people with type 2 diabetes. This study by the Diabetes Prevention Program Research Group is an important step towards developing a targeted approach to diabetes prevention.

The study had a well conceived question, which was creatively operationalised and evaluated. The analysis showed that both a lifestyle intervention and metformin were highly effective. This finding is important to nurses because it forms a basis for developing practical initiatives with a great deal of confidence.

Lifestyle modifications can make a sustainable and substantial difference in delaying the onset of diabetes, but how achievable is this lifestyle programme? In this study, even the "standard" lifestyle recommendations may be more intensive than many current practices and the "intensive" intervention requires considerable resources. It is important to determine if the human and economic resources needed to implement it are available. Cost effectiveness analysis to support either metformin or intensive lifestyle modification as the strategy of choice in practice has not been published.

This study is timely and relevant to nurses working in settings that provide for continued contact over time with ostensibly "well" populations such as those encountered in public health, community health centres, and occupational health settings. Nurses in such settings should have the flexibility and mandate to build on the counselling role that has been highlighted in this study.

Although the population was described in terms of ethnicity and gender, socioeconomic status was not considered. It is possible that other variables are important. It will be important to see if future studies can replicate and further validate the findings of this study, and to determine if the results are generalisable to all groups. Beverly Greene, RN, CNS, MN Clinical Nurse Specialist Region 3 Health Authority Fredericton, New Brunswick, Canada 